\title{
Preliminary Study of the Rhenium Addition on the Structure and Mechanical Properties of Tungsten Heavy Alloy
}

\author{
Paweł Skoczylas *(D) and Mieczysław Kaczorowski
}

Department of Mechanics and Armament Technology, Faculty of Mechanical and Industrial Engineering, Warsaw University of Technology, Narbutta 85, 02-524 Warsaw, Poland; mieczyslaw.kaczorowski@gmail.com

* Correspondence: pawel.skoczylas@pw.edu.pl

check for updates

Citation: Skoczylas, P.; Kaczorowski, M. Preliminary Study of the Rhenium Addition on the Structure and Mechanical Properties of Tungsten Heavy Alloy. Materials 2021, 14, 7365. https://doi.org/10.3390/ma14237365

Academic Editor: Thomas Niendorf

Received: 27 October 2021

Accepted: 25 November 2021

Published: 30 November 2021

Publisher's Note: MDPI stays neutral with regard to jurisdictional claims in published maps and institutional affiliations.

Copyright: (c) 2021 by the authors. Licensee MDPI, Basel, Switzerland. This article is an open access article distributed under the terms and conditions of the Creative Commons Attribution (CC BY) license (https:/ / creativecommons.org/licenses/by/ $4.0 /)$.

\begin{abstract}
The results of structure and mechanical property investigations of tungsten heavy alloy (THA) with small additions of rhenium powder are presented. The material for the study was prepared using liquid phase sintering (LPS) of mixed and compacted powders in a hydrogen atmosphere. From the specimens, the samples for mechanical testing and structure investigations were prepared. It follows from the results of the microstructure observations and mechanical studies, that the addition of rhenium led to tungsten grain size decreasing and influencing the mechanical properties of W-Ni-Fe-Co base heavy alloy.
\end{abstract}

Keywords: tungsten heavy alloy; rhenium addition; microstructure; mechanical properties; liquid phase sintering

\section{Introduction}

Tungsten heavy alloys (THA) belong to the group named weight heavy alloys (WHA), which are characterized with very high density and good mechanical properties [1-16]. One of the special applications is kinetic energy penetrators (KEP) [17-24]. Up to today, these penetrators were commonly made of depleted uranium (DU), which is technologically easier and better from a ballistic point of view (depth of penetration). However, because of its radioactivity, DU penetrators are successively replaced with tungsten heavy alloys; because of the very high melting point of tungsten $\left(3420{ }^{\circ} \mathrm{C}\right)$, the powder metallurgy (PM) had to be used. Among a few methods of sintering, liquid phase sintering (LPS) is most often used [1-3,7,15,25-28]. As was already said, DU penetrators exceed the THA with depth of penetration, which is caused by so-called "self-sharpening" effects of ascribed adiabatic shear bands (ASB) formation [28-33]. ASB forms in THA penetrators (Figure 1), but only occasionally because of specific microstructures consisting of hard 30-40 $\mu \mathrm{m}$ size tungsten grains embedded in a relatively soft matrix. Such a specific microstructure (sometimes called composite) forces the ASB to spread in a zigzag path. However, we suspect that the spreading of ASB would be much easier in THA with finer tungsten grains. The size of tungsten grains is controlled with an LPS parameter (time and temperature) $[1,7,15,27,33]$, but also can decrease with some alloying species (e.g., $\operatorname{Re}$ addition $[27,34-44])$. Therefore, we conducted a preliminary investigation concerning the influence of rhenium on the microstructure and mechanical properties of W-Ni-Fe-Co type heavy alloy. The main goal of the study is to verify if and how much Re addition influences the tungsten grain size? 


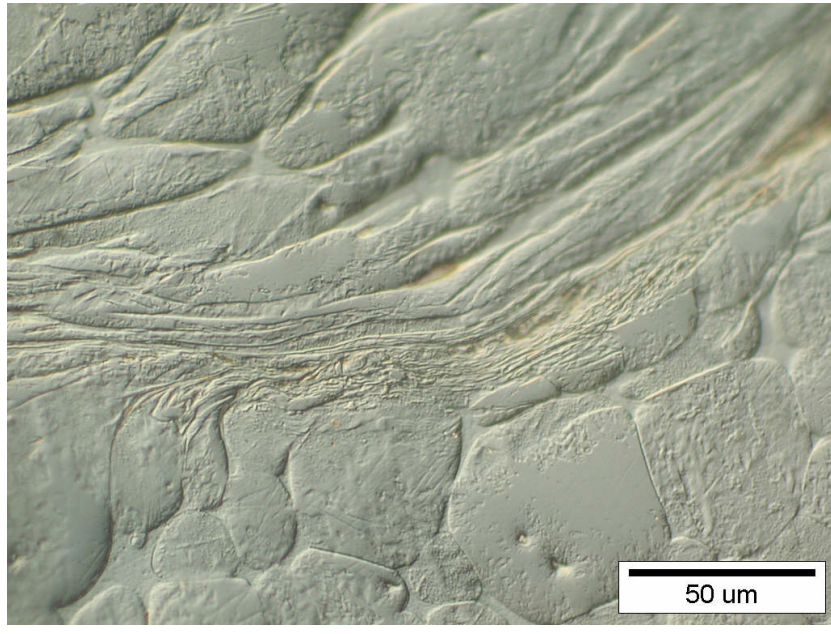

(a)

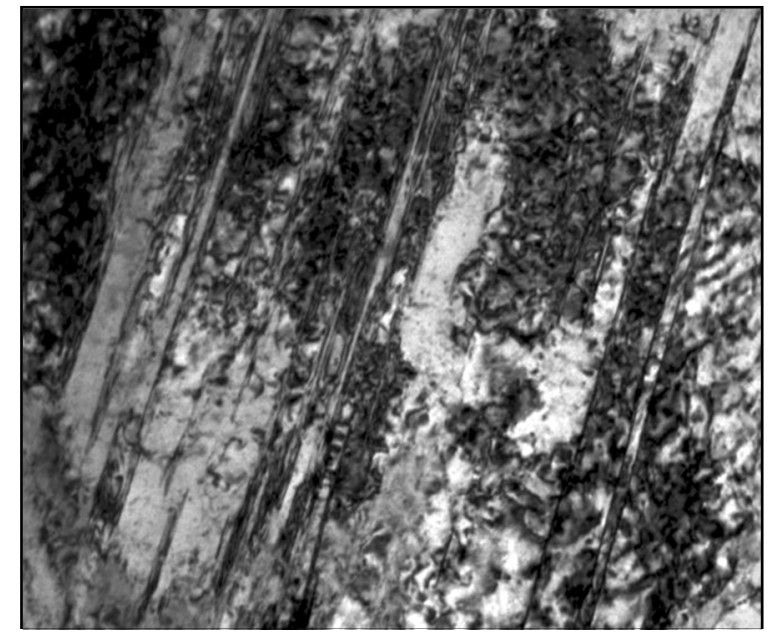

(b)

Figure 1. The example of ASB in the tungsten heavy alloys penetrator: (a) metallographic photo, (b) transmission electron micrograph $(\mathrm{TEM})$ area $\times 40.000$.

\section{Experimental Procedure}

The tungsten alloy W90.8Ni6.2Fe1.2Co1.8 designated as PR-100 was selected for the study. This alloy was "base" alloy; its composition was modified with a small amount of rhenium. The composition of three THA with rhenium selected for the study was calculated this way, to assure the same density of the alloys. Since density of rhenium $\left(20.02 \mathrm{Mg} / \mathrm{m}^{3}\right)$ is comparable with tungsten $\left(19.30 \mathrm{Mg} / \mathrm{m}^{3}\right)$, the rhenium addition replaced tungsten in the powder mixture. The chemical composition of alloys is provided in Table 1. High purity tungsten, nickel and iron powders were mixed with pure rhenium. The rhenium powder had to be powdered to a size of about 3-10, mechanically in agate mortar. The powder components were mixed, compressed, and then sintered in a hydrogen atmosphere, according to the schedule provided in Figure 2.

Table 1. Chemical composition of the alloys.

\begin{tabular}{cccccc}
\hline \multirow{2}{*}{$\begin{array}{c}\text { Alloy } \\
\text { Designation }\end{array}$} & $\mathbf{W}$ & $\mathbf{N i}$ & $\mathbf{F e}$ & $\mathbf{C o}$ & $\mathbf{R e}$ \\
\cline { 2 - 5 } & 90.80 & & & & - \\
PR-100 & 90.00 & 6.2 & 1.2 & 1.8 & 0.80 \\
Re-1 & 89.25 & & & 1.55 \\
Re-2 & 88.40 & & & & 2.40 \\
Re-3 & & &
\end{tabular}

Liquid phase sintering was carried out under a hydrogen atmosphere in a Vacum Industries chamber furnace (Vacuum Industries, Inc., Somerville, MA, USA). Proper sintering consisted of a 5 min soak-time at the temperature of $1520^{\circ} \mathrm{C}(7$ stage on the graph, Figure 2). Starting from a temperature of $1100{ }^{\circ} \mathrm{C}$ (point END on the graph), the atmosphere was changed from hydrogen to nitrogen. After LPS, the specimens in the shape of cylindrical rods with a diameter of $18 \mathrm{~mm}$ and length of $510 \mathrm{~mm}$, were subjected to heat treatment in a vacuum furnace to remove the hydrogen introduced during the liquid phase of sintering. The heat treatment annealing was carried out in a vacuum at $1100{ }^{\circ} \mathrm{C}$ for $180 \mathrm{~min}$. In the final step, the rods were removed and flash cooled in water.

First, the density of the alloys were measured using the Archimedes method. The microstructure investigations were carried out using conventional metallography. The observations of the microstructure were carried out on the Nikon Eclipse MA-200 Microscope (Nikon Corporation; Tokyo, Japan), using objectives with a magnification of 50 to $1000 \times$. The typical microstructure photos were digitalized for quantitative analysis. For 
the qualitative analysis, both longitudinal and transverse cross sections of the specimen were used. The mechanical testing was used for evaluation of tensile strength $-R_{m}$, yield stress $-R_{p} 0.2$, and elongation $-A_{5}$. For the mechanical testing standard, quintuple samples with a diameter of $5 \mathrm{~mm}$ were used. The tests were carried out on the Instron model 1115 testing machine (Instron; Norwood, MA, USA) with a $100 \mathrm{kN}$ head and a traverse speed of $1 \mathrm{~mm} / \mathrm{min}$.

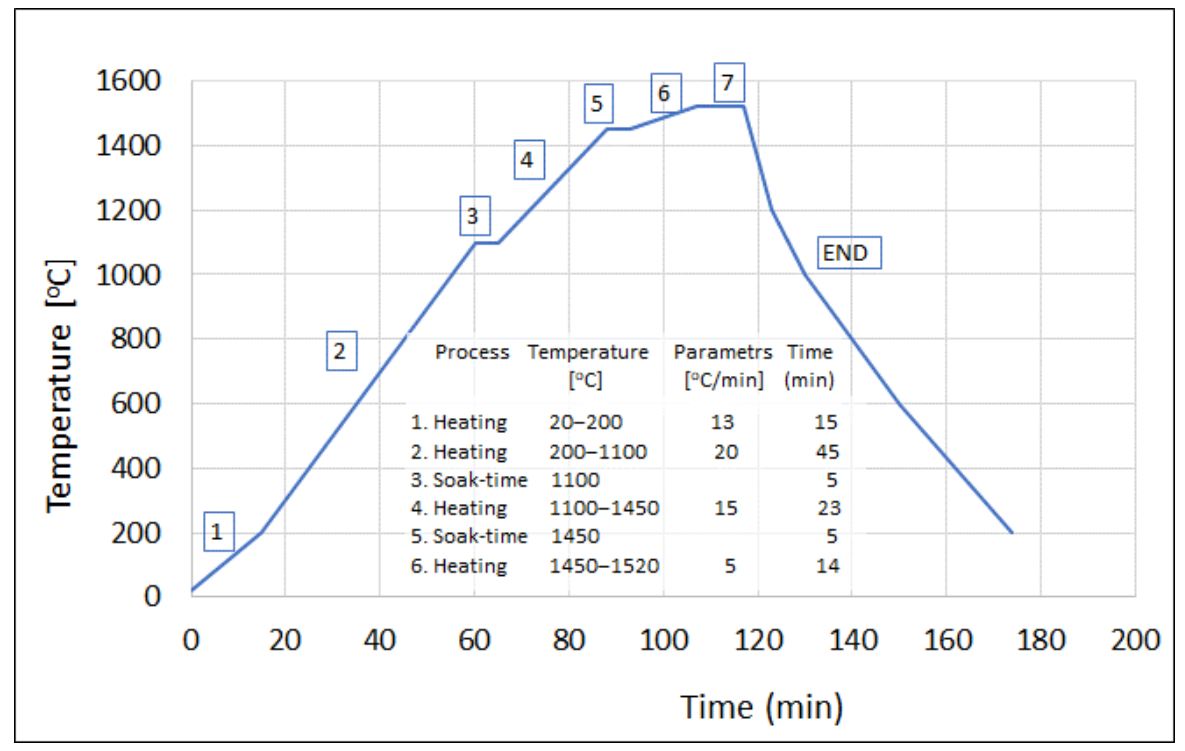

Figure 2. Scheme of single heat treatment: (stage 7) 20 min liquid phase sintering at temperature $1520{ }^{\circ} \mathrm{C}$.

Except for the standard mechanical testing, a hardness measurement of tungsten grains and the Ni-based matrix were performed. The experiment was carried out on a Future-Tech FM-810 tester (Future-Tech Corp; Tokyo, Japan) under a load of $25 \mathrm{~g}$ (dwell time: $15 \mathrm{~s}$ ). The research was carried out on previously performed metallographic specimens.

The analysis of the chemical composition, in particular of the rhenium content in the tungsten grains, was carried out on a scanning electron microscope (Carl Zeiss Microscopy $\mathrm{GmbH}$, Jena, Germany) by Zeiss Ultra Plus with an attached EDS system (Quantax 400) by Bruker.

\section{Results}

\subsection{Results of Density Measurements}

The results of density testing are provided in Table 2. It follows from Table 2 that the density of all alloys is almost the same and the calculated values equal the calculated one; this means also that the specimens are free of discontinuities and pores.

Table 2. Density of alloys.

\begin{tabular}{ccc}
\hline \multirow{2}{*}{ Alloy Designation } & \multicolumn{2}{c}{ Density $\left.\mathbf{( M g} / \mathbf{m}^{\mathbf{3}}\right)$} \\
\cline { 2 - 3 } & Calculated & Measured \\
\hline PR-100 & 17.37 & 17.35 \\
Re-1 & 17.38 & 17.37 \\
Re-2 & 17.39 & 17.35 \\
Re-3 & 17.40 & 17.35 \\
\hline
\end{tabular}

\subsection{Results of Mechanical Testing}

The results of the mechanical testing are presented in Table 3. It is visible from the table that the rhenium addition influences tensile strength, yield stress, and elongation, 
but this influence is different and depends on the amount of rhenium. Figure 3 displays the graphic illustration of the dependence of tensile strength, ultimate tensile stress, and elongation in the function of rhenium content. Figure 4 displays the stress-strain diagram for the sample with $0.8 \mathrm{wt} . \%$ Re.

It is visible from the graphs that the rhenium content increase causes an almost simultaneous increase of tensile strength (Figure 3a). In the case of ultimate stress, the maximum value $R_{p 0.2}$ is observed for $1.5 \%$ of $R e$ and then it decreases with the Re increase (Figure $3 \mathrm{~b}$ ). The elongation value is almost constant up to $1.55 \%$ Re and then drops drastically for $2.4 \%$ Re (Figure 3c). The behavior of elongation with rhenium content was expected on the basis of literature information, where it can be found that an excess of rhenium causes brittleness of tungsten alloys.

(a)

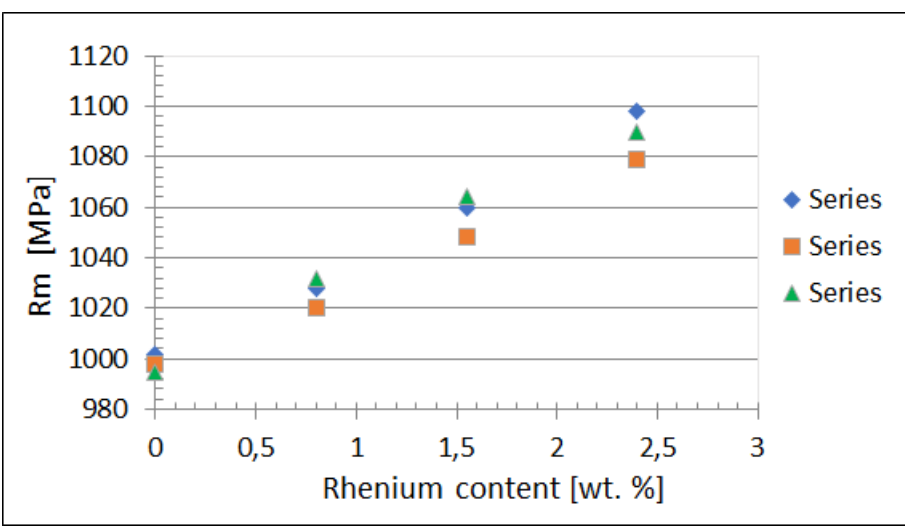

(b)

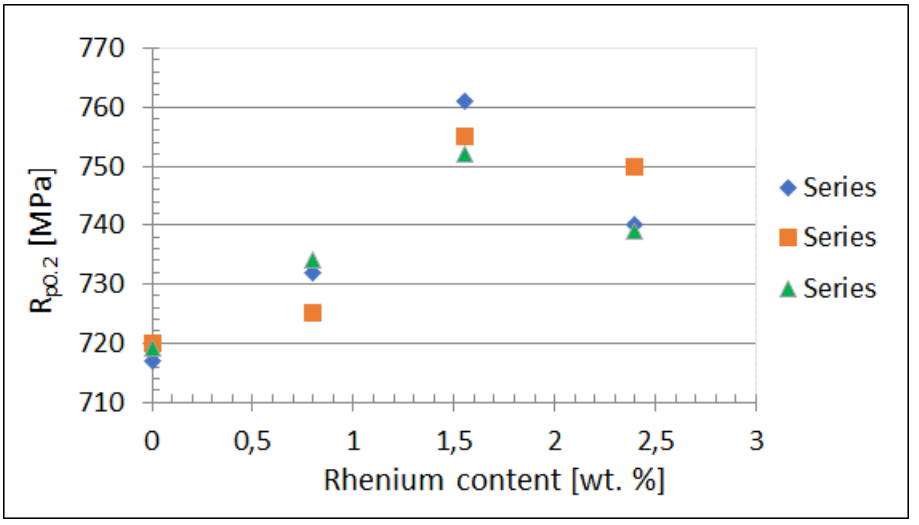

(c)

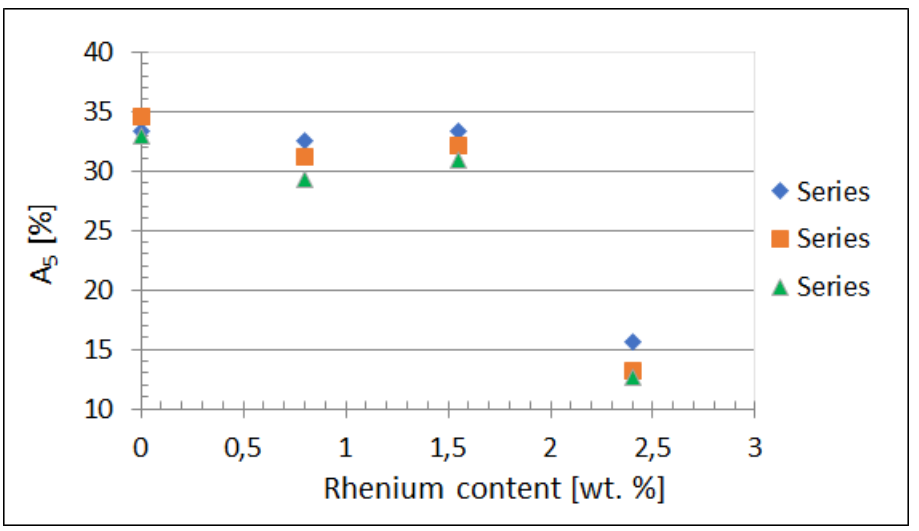

Figure 3. The results of tensile tests as a function of sintering cycles: (a) tensile strength, (b) yield strength, and (c) elongation. 
Table 3. The results of mechanical testing.

\begin{tabular}{|c|c|c|c|}
\hline \multirow{2}{*}{ Alloy Type } & \multicolumn{3}{|c|}{ Mechanical Properties } \\
\hline & $\mathrm{R}_{\mathrm{p} 0.2}(\mathrm{MPa})$ & $\mathrm{Rm}$ (MPa) & $A_{5}(\%)$ \\
\hline \multirow{3}{*}{ Pr-100 } & 717 & 1002 & 33.4 \\
\hline & 720 & 998 & 34.5 \\
\hline & 719 & 995 & 32.9 \\
\hline Average values & $719 \pm 2$ & $998 \pm 4$ & $33.6 \pm 0.8$ \\
\hline \multirow{3}{*}{$\operatorname{Re}-1$} & 732 & 1028 & 32.5 \\
\hline & 725 & 1020 & 31.2 \\
\hline & 734 & 1032 & 29.3 \\
\hline Average values & $730 \pm 5$ & $1027 \pm 6$ & $31.0 \pm 1.6$ \\
\hline \multirow{3}{*}{$\operatorname{Re}-2$} & 761 & 1060 & 33.4 \\
\hline & 755 & 1048 & 32.1 \\
\hline & 752 & 1064 & 30.9 \\
\hline Average values & $756 \pm 5$ & $1057 \pm 8$ & $32.1 \pm 1.3$ \\
\hline \multirow{3}{*}{$\operatorname{Re}-3$} & 740 & 1098 & 15.6 \\
\hline & 750 & 1079 & 13.2 \\
\hline & 739 & 1090 & 12.6 \\
\hline Average values & $743 \pm 6$ & $1089 \pm 10$ & $13.8 \pm 1.6$ \\
\hline
\end{tabular}

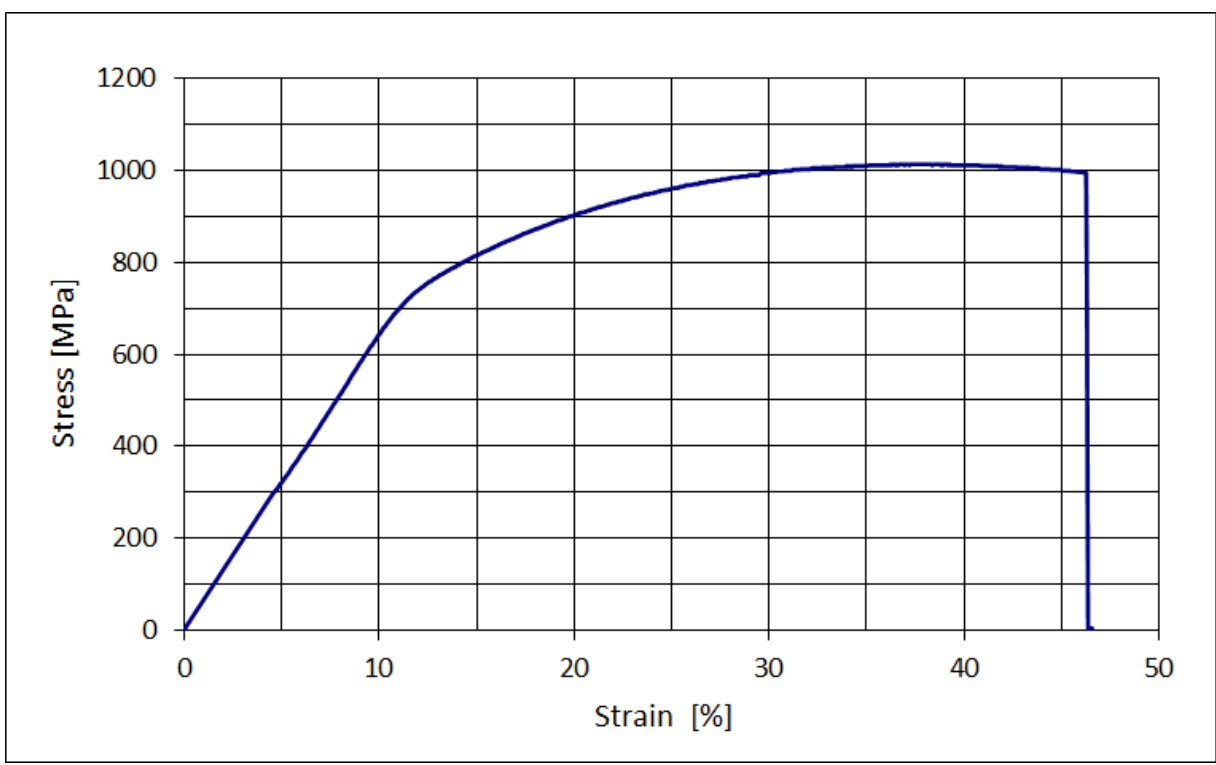

Figure 4. The stress-strain curve for the specimen $\operatorname{Re}-1(0.8 \% \operatorname{Re})$.

\subsection{Results of Microhardness Measurement}

The average values of the microhardness measurements of tungsten grains and matrix are presented in Table 4. Figure 5 shows examples of microhardness measurement in the area of tungsten grain and matrix. Average values were obtained by performing 20 measurements in tungsten grains and the matrix.

Larger microhardness scatter (standard deviation) was obtained for the measurement in the matrix. The likely cause of this is with the WHA microstructure; there may be tungsten grains under the thin warp layer. Thus, when performing the matrix measurement, the measurement in tungsten grains is partially carried out. In each of the WHA materials, the microhardness of tungsten grains is higher than the microhardness of the matrix. The microhardness of the matrix and tungsten grains in the alloy without the addition of rhenium (PR-100) is, respectively, 345 and $440 \mathrm{HV} 0.025$. With an addition of $0.80 \mathrm{wt}$ \% $\operatorname{Re}(\operatorname{Re}-1)$, no 
increase in matrix microhardness and a decrease in tungsten grain microhardness is observed. For the alloy with an intermediate amount of rhenium (Re-2), the matrix microhardness increased by approximately $30 \mathrm{HV} 0.025$ units. The microhardness of the tungsten grains, taking into account the error value, did not change. For the highest rhenium content in the alloy (Re-3), an increase in the matrix microhardness by approx. 45 HV 0.025 units is visible. The microhardness of tungsten grains increases by $30 \mathrm{HV} 0.025$ units.

Table 4. The results of microhardness measurements.

\begin{tabular}{ccc}
\hline \multirow{2}{*}{ Alloy Designation } & \multicolumn{3}{c}{ HV 0.025 } \\
\cline { 2 - 3 } & Matrix & Tungsten Grain \\
\hline PR-100 & $345 \pm 15$ & $440 \pm 12$ \\
Re-1 & $340 \pm 15$ & $398 \pm 18$ \\
Re-2 & $380 \pm 21$ & $455 \pm 13$ \\
Re-3 & $398 \pm 23$ & $470 \pm 12$ \\
\hline
\end{tabular}

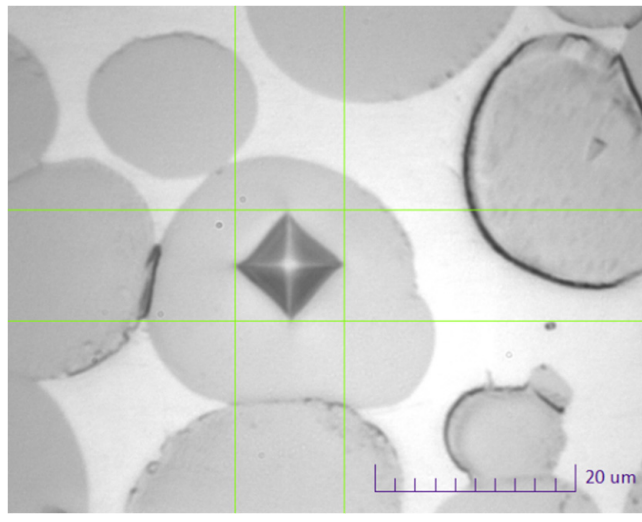

(a)

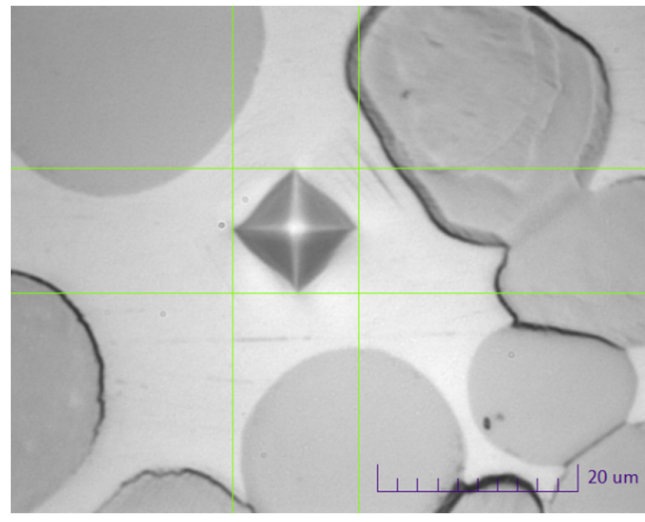

(b)

Figure 5. Sample photos of measuring microhardness of tungsten grains (a) and matrix (b).

\subsection{Microstructure Observations}

In Figure 6, the examples of THA microstructure are depicted. The micrographs are specially given at the same magnification to allow immediate comparison of the tungsten grains' diameter.

The microstructure of all WHA materials is homogeneous, consisting of shaped, elliptical tungsten grains in the matrix of the binding phase. No pore clusters were found in the microstructure.

For each sample, at least 100 measurements of tungsten grains were carried out. Then two of them, the maximum and minimum values, were removed, and the rest were used for statistical evaluation. The results of the tungsten grain size measurement are provided in Table 5. The values provided in Table 5 are the mean diameter converted to the area of the circle.

Table 5. The average tungsten grain size.

\begin{tabular}{ccc}
\hline Alloy Designation & Re Content (wt.\%) & Tungsten Grain Size $(\mu \mathrm{m})$ \\
\hline PR-100 & & $33.1 \pm 4.6$ \\
Re-1 & 0.80 & $32.8 \pm 4.6$ \\
Re-2 & 1.55 & $26.1 \pm 3.1$ \\
Re-3 & 2.40 & $20.6 \pm 3.4$ \\
\hline
\end{tabular}




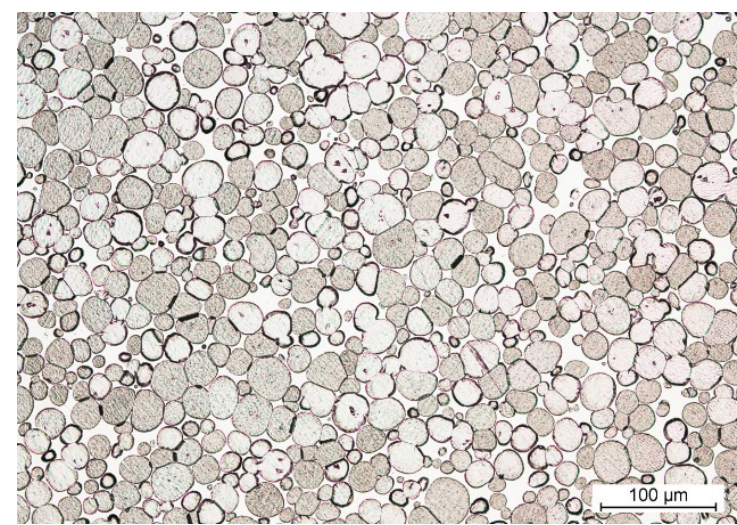

(a)

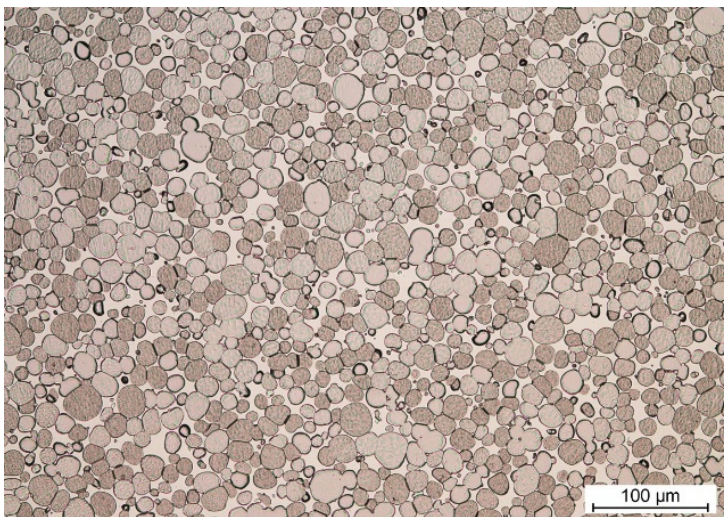

(c)

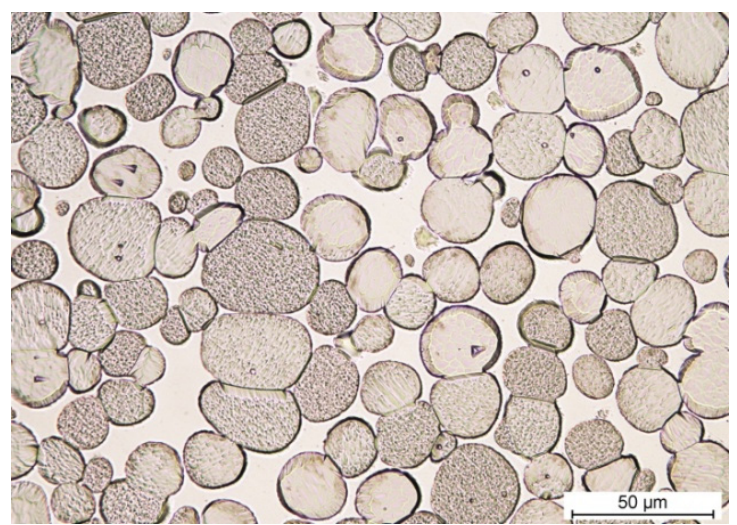

(b)

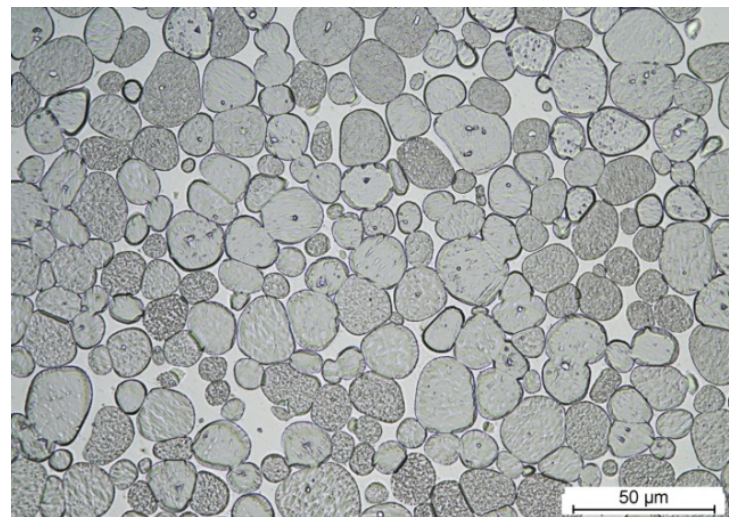

(d)

Figure 6. The microstructure of THA: (a,b) without addition of $\operatorname{Re}(P R-100),(\mathbf{c}, \mathbf{d})$ with 2.4 wt.\% $\operatorname{Re}(\operatorname{Re}-3),(\mathbf{a}, \mathbf{c})$ mag. 200× and $(\mathbf{b}, \mathbf{d})$ mag. $500 \times$.

It follows from Table 5 that the increase of Re content causes the systematic decrease of tungsten grain size.

The average diameter of the tungsten grains in the WHA material without the addition of Re is $33 \mu \mathrm{m}$. Grain size reduction in the material with the lowest Re content ( $0.8 \mathrm{wt} . \%)$ is at the level of just a few percent. Tungsten grain size reduction in an alloy with an intermediate Re content (1.55 wt.\%.) is $20 \%$. In the WHA material with the highest Re addition (2.4 wt.\%), the tungsten grain size was reduced by $40 \%$.

\subsection{Chemical Microanalysis Tungsten Grains and Matrix}

The microanalysis of studied alloys was performed in a scanning electron microscope equipped with am EDX attachment. The aim of this study was to evaluate the concentration of rhenium in tungsten grains and the matrix. The results of the chemical composition study are depicted in Table 6. Examples of EDS analysis sites are shown in Figure 7.

Table 6. Results of microanalysis of tungsten grains and matrix.

\begin{tabular}{cccc}
\hline \multirow{2}{*}{ Alloy Designation } & \multicolumn{2}{c}{ Re Content Mass Norm. (\%) } & $\begin{array}{c}\text { Chemical } \\
\text { Composition (wt.\%) }\end{array}$ \\
\cline { 2 - 3 } & Tungsten Grains & Matrix & 0.80 \\
Re-1 & 0.82 & 0.73 & 1.55 \\
$\operatorname{Re}-2$ & 1.85 & 0.49 & 2.40 \\
Re-3 & 2.46 & 0.82 & \\
\hline
\end{tabular}




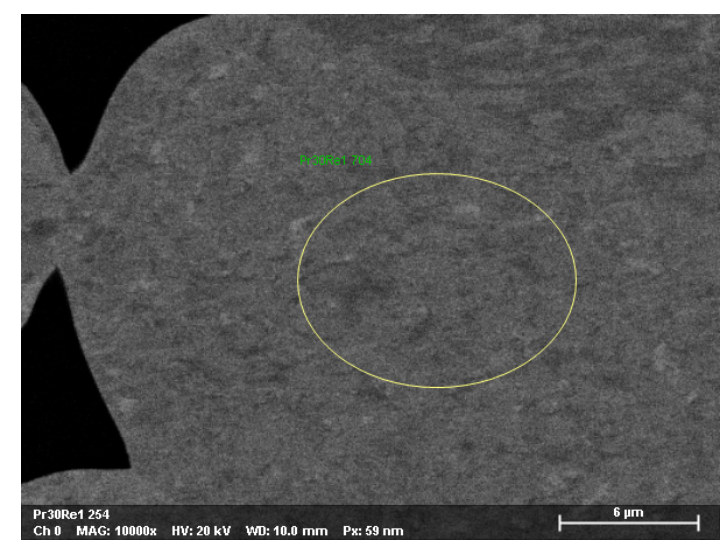

(a)

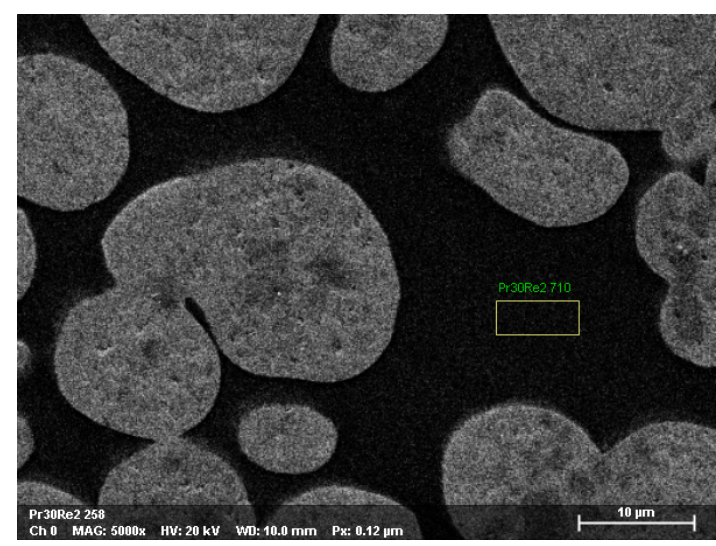

(b)

Figure 7. SEM micrograph with marked places of EDS analysis in the area of tungsten grains (a) and matrix (b).

It is visible from the tables that rhenium occurred either in tungsten grains or the matrix, but the solubility of rhenium in tungsten grains reaching $2.46 \mathrm{wt} . \%$ is much higher in tungsten grains than in the Ni-based matrix, where it arrives at $0.82 \mathrm{wt} . \%$ only.

The solubility of rhenium in tungsten grains is comparable to the percentage of rhenium in the chemical composition of individual WHA materials.

\section{Discussion of Results}

For many years, work has been carried out to increase the armor penetration by kinetic anti-tank missiles. The armor penetration depth of this type of ammunition depends on many factors, including (at the same projectile velocity) the density and mechanical properties of the penetrator used. One of the directions of development of this type of ammunition is research in the field of modification of the chemical composition and heat and mechanical treatment processes of the penetrator's construction material, in the direction of obtaining an appropriate metallographic structure ensuring a self-sharpening effect. One of the possible methods of increasing the penetration capacity of the armor by penetration may be by adding rhenium to the WHA chemical composition. Due to its density higher than tungsten, rhenium does not lower the WHA material density, improves strength properties, and decreases the size of tungsten grains in the alloy microstructure. The advantages of rhenium presented above may facilitate the formation and spreading of adiabatic shear bands (ASB) during the target penetration process and the self-sharpening effect.

The Re-W binary system $[45,46]$ indicates the formation of solid solutions between tungsten and rhenium from the temperature of $1500{ }^{\circ} \mathrm{C}$ to the melting point of individual elements. The maximum solubility of rhenium in tungsten at the temperature of $3000{ }^{\circ} \mathrm{C}$ is $37 \%$. The solubility at $1500{ }^{\circ} \mathrm{C}$ is $28 \%$. The solubility of tungsten in rhenium at the temperature of $2800{ }^{\circ} \mathrm{C}$ is $20 \%$, and at the temperature of $1500{ }^{\circ} \mathrm{C}$ it is $12 \%$.

Rhenium solubility in nickel at $1620{ }^{\circ} \mathrm{C}$ is $17.4 \%$. It should be emphasized that the attached system displays equilibrium with the $\mathrm{W}$-Re phase above the temperature of $1500{ }^{\circ} \mathrm{C}$.

The presented results of the analysis of the chemical composition of tungsten grains by the EDS method confirm the formation of solid solutions of tungsten with rhenium. The solubility of rhenium was confirmed both in the binding phase, which was a solution on a nickel matrix, and in tungsten grains. The rhenium content in tungsten grains is comparable to the percentage of rhenium powder added to individual mixtures (Table 2).

In traditional $\mathrm{W}-\mathrm{Ni}-\mathrm{Fe}$ alloys, along with increasing the amount of tungsten, the theoretical density increases, and the amount of matrix decreases. This translates into a change in the microstructure, an increase in the share of low-energy intercrystalline boundaries between the contacting tungsten grains. Increasing the amount of tungsten in the alloy causes an increase in hardness, but when its' optimal amount is exceeded, the strength, plasticity, and impact properties decrease (e.g., in W-Ni-Fe alloys with a content 
of more than $96 \%$ by weight of tungsten, the values above the mentioned parameters drop significantly [15]). The formation of solid solutions of rhenium and tungsten enables the production of high-density tungsten heavy alloys without losing mechanical properties. The high density of rhenium and the fact of its steaming in the tungsten grains allows it to maintain the optimal amount of the matrix, without increasing the direct contact points between the tungsten grains (called contiguity) and without reducing the strength and impact toughness value.

\section{Conclusions}

Based on the research, it can be concluded that at given LPS parameters:

- Rhenium is dissolved in the tungsten grains to a content of at least $2.4 \%$ by mass.

- Rhenium promotes the grinding of tungsten grains. With $1.5 \mathrm{wt} . \%$, changes in the microstructure are visible; there is a marked reduction in the size of the tungsten grains. With the increase in the rhenium content in the alloy, the size distribution of the measured grains decreases.

- Addition of Re has a relatively small influence on tungsten grain hardness $(\sim 7 \%)$, but causes a visible increase of matrix hardness ( 15\%).

- The increase of rhenium content increases the porosity. It can be suggested that increased porosity decreases plasticity by increasing the matrix sensitivity on the stress concentration factor. This in turn could explain the drop in elongation in cases with higher (2.4 wt.\%) Re content.

- The addition of rhenium increases the strength properties of WHA. The value of tensile strength and proof strength increases with increasing shares of rhenium in WHA.

- The addition of rhenium reduces the plasticity of the WHA. As the rhenium content in WHA increases, the elongation decreases. Initially, for the lower amount of rhenium in WHA ( 0.8 and $1.55 \%$ by weight), the reduction in plasticity is slight $-4 \%$ for the alloy without the addition of Re. With a higher rhenium content in WHA $(2.4 \%)$, the decrease in plasticity is significant-nearly $60 \%$.

In future research, we would like to study the influence of Re content on the contiguity parameter. Moreover, we are going to carry out a TEM observation using the thin foil method. In this study, we will concentrate on the very subtle structure of the matrix and the region on the tungsten grain-matrix boundaries. Since we are involved into materials dedicated to military application, we will try to see if and how the rhenium addition influences W-Ni-Co type WHA.

Author Contributions: Conceptualization, P.S.; methodology, P.S. and M.K.; validation, P.S. and M.K.; formal analysis, P.S.; investigation, P.S. and M.K.; writing-original draft preparation, P.S. and M.K.; writing-review and editing, P.S. and M.K.; funding acquisition, P.S. All authors have read and agreed to the published version of the manuscript.

Funding: This research was supported by the small grant of the Scientific Council of Mechanical Engineering, Warsaw University of Technology.

Institutional Review Board Statement: Not applicable.

Informed Consent Statement: Not applicable.

Data Availability Statement: Not applicable.

Conflicts of Interest: The authors declare no conflict of interest.

\section{References}

1. German, R.M. Liquid Phase Sintering; Plenum Press: Seoul, Korea, 1985.

2. Skoczylas, P.; Goroch, O.; Gulbinowicz, Z.; Barcz, K.; Kaczorowski, M. Research into the Production of Tungsten Heavy Alloys with Specific Mechanical Properties, Problems of Mechatronics. Armament Aviat. Saf. Eng. 2019, 10, $23-36$.

3. Lassner, E.; Schubert, W.D. Tungsten: Properties, Chemistry, Technology of the Element, Alloys, and Chemical Compounds; Springer: Boston, MA, USA, 1999. 
4. Kunčická, L.; Kocich, R.; Klečková, Z. Effects of Sintering Conditions on Structures and Properties of Sintered Tungsten Heavy Alloy. Materials 2020, 13, 2338. [CrossRef]

5. Das, J.; Ravi Kiran, U.; Chakraborty, A.; Eswara, N. Hardness and tensile properties of tungsten based heavy alloys prepared by liquid phase sintering technique. Int. J. Refract. Met. Hard Mater. 2009, 27, 577-583. [CrossRef]

6. Skoczylas, P.; Kaczorowski, M. The influence of cyclic sintering on the structure and mechanical properties of Tungsten Heavy Alloy. Arch. Foundry Eng. 2016, 16, 131-136. [CrossRef]

7. Skoczylas, P.; Gulbinowicz, Z.; Goroch, O. Microstructure and Properties of Tungsten Heavy Alloy Connections Formed during Sintering with the Participation of the Liquid Phase. Materials 2020, 13, 4965. [CrossRef]

8. Lu, Y.; Qiu, X.; Ruan, Y.; Luo, C.; Xing, F. Effect of Ti on Microstructure and Properties of Tungsten Heavy Alloy Joint Brazed by CuAgTi Filler Metal. Materials 2019, 12, 1057. [CrossRef] [PubMed]

9. Yu, Y.; Er-de, W. Microstructure and properties of liquid phase sintered tungsten heavy alloys by using ultra-fine tungsten powders. Trans. Nonferrous Met. Soc. China 2004, 14, 912-917.

10. Kaczorowski, M.; Skoczylas, P.; Krzyńska, A.; Kaniewski, J. The strengthening of weight heavy alloys during heat treatment. Arch. Foundry Eng. 2012, 12, 75-80. [CrossRef]

11. Hyung, B.W.; Hee, H.M.; Pyo, K.E. Heat treatment behavior of tungsten heavy alloy. Solid State Phenom. 2006, 118, 35-40.

12. Katavić, B.; Odanović, Z.; Burzi, M. Investigation of the rotary swaging and heat treatment on the behavior of W- and $\gamma$ - phase in PM 92.5W-\%-Ni-2.5Fe-0.26Co heavy alloy. Mater. Sci. Eng. A 2008, 492, 337-345. [CrossRef]

13. Katavić, B.; Nikaćević, M.; Odanović, Z. Effect of cold swaging and heat treatment on properties of the P/M 91W-6Ni-3Co heavy alloy. Sci. Sinter. 2008, 40, 319-331. [CrossRef]

14. Sunwoo, A.; Groves, S.; Goto, D. Effect of matrix alloy and cold swaging on micro-tensile properties of tungsten heavy alloys. Mater. Lett. 2006, 60, 321-325. [CrossRef]

15. Edmonds, D.V. Structure-property relationships in sintered heavy alloys. Refract. Met. Hard Mater. 1991, 10, 15-26. [CrossRef]

16. Durlu, N.; Çalişkan, N.K.; Bor, Ş. Effect of swaging on microstructure and tensile properties of W-Ni-Fe alloys. Int. J. Refract. Met. Hard Mater. 2014, 42, 126-131. [CrossRef]

17. German, R.M. Critical developments in tungsten heavy alloys. In Proceedings of the 1th International Conference on Tungsten Tungsten Alloys, Arlington, VA, USA, 15-18 November 1992; pp. 3-13.

18. Magness, L.S.; Kapoor, D. Flow-softening tungsten composites for kinetic energy penetrator applications. In Proceedings of the 2nd International Conference on Tungsten and Refractory Metals, McLean, VA, USA, 17-19 October 1994.

19. Lanz, W.; Odermatt, W.; Weihrauch, G. Kinetic energy projectiles: Development history, state of the art, trends. In Proceedings of the 19th International Symposium of Ballistics, Interlaken, Switzerland, 7-11 May 2001.

20. Kumbhar, K.; Senthil, P.P.; Gogia, A.K. Microstructural observations on the terminal penetration of long rod projectile. Def. Technol. 2017, 6, 413-421. [CrossRef]

21. Kruszka, L.; Janiszewski, J.; Grazka, M. Experimental and Numerical Analysis of Al6063 Duralumin Using Taylor Impact Test, EPJ Web of Conference; EDP Sciences: Les Ulis, France, 2012; Volume 26, p. 201201062.

22. Kennedy, C.; Murr, L.E. Comparison of tungsten heavy-alloy rod penetration into ductile and hard metal targets: Microstructural analysis and computer simulations. Mater. Sci. Eng. A 2002, 325, 131-143. [CrossRef]

23. Hauver, G.E.; Melani, A. Behavior of Segmented Rods during Penetration, Technical Report BRL-TR-3129; Army Ballistic Research Lab Aberdeen Proving Ground: Aberdeen, MD, USA, 1990.

24. Arnold, W. Tungsten heavy alloys for multiple impact applications. In AIP Conference Proceedings; AIP: College Park, MA, USA, 2004; pp. 1319-1322.

25. Rabin, B.H.; Bose, A.; German, R.M. Characteristics of Liquid Phase Sintered Tungsten Heavy Alloys. Int. J. Powder Metall. 1989, $25,21-27$.

26. Bose, A.; German, R.M. Sintering atmosphere effects on tensile properties of heavy alloys. Metall. Trans. A Phys. Metall. Mater. Sci. 1988, 19, 66-77. [CrossRef]

27. Kaczorowski, M.; Skoczylas, P.; Krzyńska, A. The influence of Fe content on spreading ability of tungsten heavy alloys matrix on tungsten surface. Arch. Foundry Eng. 2011, 11, 103-106.

28. Majewski, T. Technologiczne Uwarunkowania Właściwości Użytkowych Spieków Ciężkich W-(Fe, Ni, Re); Wojskowa Akademia Techniczna: Warszawa, Poland, 2013.

29. Motyl, K.; Magier, M.; Borkowski, J.; Zygmunt, B. Theoretical and experimental research of anti-Tank kinetic penetrator ballistics. Bull. Pol. Acad. Sci. Tech. Sci. 2017, 65, 399-404. [CrossRef]

30. Magier, M. The role of adiabatic shear bands effect in penetration process. Probl. Tech. Uzbroj. 2018, 147, 7-17. [CrossRef]

31. Kaczorowski, M.; Nowak, W.; Skoczylas, P.; Rafalski, M. Zjawiska występujące w rdzeniach pocisków podczas penetracji płyty, Materiały konferencyjne, wydanie specjalne XVI konferencji naukowo-technicznej. Uzbrojenie 2007, 2007, $213-219$.

32. Yadav, S.; Ramesh, K.T. The dynamic behavior of a tungsten-hafnium composite for kinetic energy penetrator applications. In Proceedings of the 4th International Conference on Tungsten Refractory Metals and Alloys, Lake Buena Vista, FL, USA, 17-19 November 1997; pp. 111-117.

33. Kaczorowski, M.; Skoczylas, P. Kształtowanie struktury i właściwości wolframowych stopów ciężkich o przeznaczeniu specjalnym", Problemy Mechatroniki. Uzbroj. Lot. Inżynieria Bezpieczeństwa 2015, 6, 27-40. 
34. Ravi Kiran, U.; Panchal, A.; Prem Kumar, M.; Sankaranarayana, M.; Nageswara Rao, G.V.S.; Nandy, T.K. Refractory metal alloying: A new method for improving mechanical properties of tungsten heavy alloys. J. Alloys Compd. 2017, 709, 609-619. [CrossRef]

35. Natarajan, S.; Gopalan, V.; Rajan, R.A.A.; Jen, C.-P. Effect of Rare Earth Metals (Y, La) and Refractory Metals (Mo, Ta, Re) to Improve the Mechanical Properties of W-Ni-Fe Alloy-A Review. Materials 2021, 14, 1660. [CrossRef]

36. Annamalai, A.R.; Muthuchamy, A.; Srikanth, M.; Natarajan, S.; Acharya, S.; Khisti, A.; Jen, C.-P. Powder Metallurgical Processing and Characterization of Molybdenum Addition to Tungsten Heavy Alloys by Spark Plasma Sintering. Materials 2021, $14,5756$. [CrossRef]

37. German, R.M.; Bose, A.; Kemp, P.B.; Zhang, H. Additive Effect on the Microstructure and Properties of Tungsten Heavy Alloy Composites. In Advances in Powder Metallurgy; Basbarre, T.G., Jandeska, W.F., Eds.; Metal Powder Industries Federation: Princeton, NJ, USA, 1989; Volume 2, pp. 401-414.

38. Liu, W.; Ma, Y.; Huang, B. Influence of minor elements additions on microstructure and properties of $93 \mathrm{~W}-4 \cdot 9 \mathrm{Ni}-2 \cdot 1 \mathrm{Fe}$ alloys. Bull. Mater. Sci. 2008, 31, 1-6. [CrossRef]

39. Bose, A.; Sadangi, R.; German, R.M. A review on alloying in tungsten heavy alloys. Suppl. Proc. Mater. Process. Interfaces 2012, 1, $453-465$.

40. Tan, X.; Leng, B.; Qiu, S. Influences of sub-micrometer Ta and Co dopants on microstructure and properties of tungsten heavy alloys. Trans. Nonferrous Met. Soc. China 2004, 14, 747-750.

41. Zhang, Y.; Huang, Y.; Liu, W.; Ma, Y.; Liu, J.; Liang, C. Effect of tungsten tantalum pre-alloying on the sintering structure of 90(W-Ta)-Ni-Fe alloy. J. Alloys Compd. 2022, 891, 161881. [CrossRef]

42. Annamalai, A.R.; Lakshmi, B.S. Effect of Rhenium addition on tungsten heavy alloys processed through spark plasma sintering. Ain Shams Eng. J. 2021, 12, 2957-2963.

43. Bose, A.; Jerman, G.; German, R.M. Rhenium alloying of tungsten heavy alloys. Powder Metall. Int. 1989, $21,9-13$.

44. James, R.S.; James, A.M. Fine Grain Tungsten Heavy Alloys Containing Additives. EP0323628A1, 12 July 1989.

45. Okamoto, H.; Massalski, T.B. Binary Alloy Phase Diagrams; ASM International: Materials Park, OH, USA, 1990.

46. Murray, J.L.; Bennett, L.H.; Baker, H.; Massalski, T.B. Binary Alloy Phase Diagrams; American Society for Metals: Metals Park, OH, USA, 1986. 